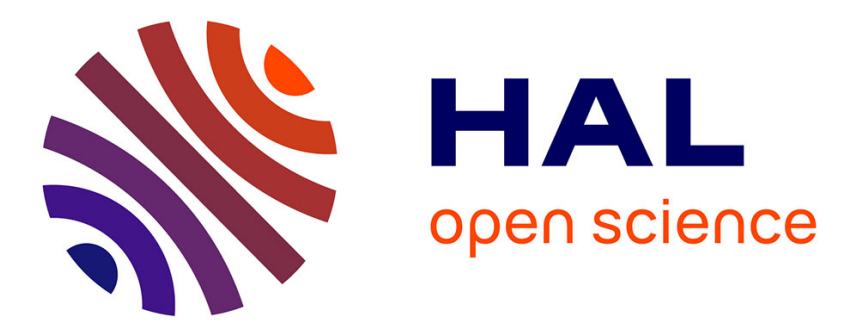

\title{
Impact of Saharan dust episodes on preterm births in Guadeloupe (French West Indies)
}

Jean-François Viel, Yoann Mallet, Christina Raghoumandan, Philippe Quénel, Philippe Kadhel, Florence Rouget, Luc Multigner

\section{- To cite this version:}

Jean-François Viel, Yoann Mallet, Christina Raghoumandan, Philippe Quénel, Philippe Kadhel, et al.. Impact of Saharan dust episodes on preterm births in Guadeloupe (French West Indies). Occupational and Environmental Medicine, 2019, 76 (5), pp.336-340. 10.1136/oemed-2018-105405 . hal-02091215

HAL Id: hal-02091215

https://hal-univ-rennes1.archives-ouvertes.fr/hal-02091215

Submitted on 11 Apr 2019

HAL is a multi-disciplinary open access archive for the deposit and dissemination of scientific research documents, whether they are published or not. The documents may come from teaching and research institutions in France or abroad, or from public or private research centers.
L'archive ouverte pluridisciplinaire HAL, est destinée au dépôt et à la diffusion de documents scientifiques de niveau recherche, publiés ou non, émanant des établissements d'enseignement et de recherche français ou étrangers, des laboratoires publics ou privés. 


\section{Impact of Saharan dust episodes on preterm births in Guadeloupe (French West Indies)}

Jean-François Viel, ${ }^{1 \bowtie}$ Yoann Mallet, ${ }^{1}$ Christina Raghoumandan, ${ }^{2}$ Philippe Quenel, ${ }^{3}$ Philippe Kadhel, ${ }^{4}$ Florence Rouget, ${ }^{1}$ Luc Multigner ${ }^{3}$

Impact of Saharan dust episodes on preterm births in Guadeloupe (French West Indies)

${ }^{1}$ Univ Rennes, CHU Rennes, Inserm, EHESP, Irset (Institut de recherche en santé, environnement et travail) - UMR_S 1085, F-35000 Rennes, France, ${ }^{2}$ Gwad'air, Air quality monitoring agency, F-97170 Petit-Bourg, France, ${ }^{3}$ Univ Rennes, Inserm, EHESP, Irset (Institut de recherche en santé, environnement et travail) - UMR_S 1085, F-35000 Rennes, France, ${ }^{4}$ Univ Antilles, CHU Guadeloupe, Univ Rennes, Inserm, EHESP, Irset (Institut de recherche en santé, environnement et travail) - UMR_S 1085, F-97000 Pointe-à-Pitre, France

Correspondence to Professor Jean-François Viel, Department of Epidemiology and Public Health, University Hospital, 2 rue Henri Le Guilloux, 35033 Rennes, France; jean-francois.viel@univrennes1.fr 


\section{ABSTRACT}

Objectives Large amounts of mineral dust are transported from their African sources in the SaharanSahel region to the Caribbean Sea, generating peak exposures to particulate matter $\leq 10 \mu \mathrm{m}\left(\mathrm{PM}_{10}\right)$. This study aimed to investigate the impact of Saharan dust episodes on preterm births in the Guadeloupe archipelago.

Methods The study population consisted of 909 pregnant women who were enrolled in the TIMOUN mother-child cohort between 2004 and 2007. Desert dust episodes were assessed from $\mathrm{PM}_{10}$ concentrations recorded at the unique background air quality monitoring station located in Pointe-àPitre. For each woman, the daily $\mathrm{PM}_{10}$ concentrations were averaged over the entire pregnancy, and the proportion of days with intense dust episodes $\left(\geq 55 \mu \mathrm{g} \mathrm{PM} 10 / \mathrm{m}^{3}\right)$ during pregnancy was calculated. Weighted logistic regression models adjusting for known individual socio-medical risk factors were used to estimate odds ratios (ORs) and 95\% confidence intervals (Cls) for preterm birth. Results During pregnancy, the mean $\mathrm{PM}_{10}$ concentrations ranged from 13.17 to $34.92 \mu \mathrm{g} / \mathrm{m}^{3}$, whereas the proportion of intense dust events ranged from 0.00 to $19.41 \%$. Increased adjusted ORs were found for both the mean $\mathrm{PM}_{10}$ concentrations and the proportion of intense dust events (OR $1.40,95 \% \mathrm{Cl} 1.08$ to 1.81 , and $\mathrm{OR} 1.54,95 \% \mathrm{Cl} 1.21$ to 1.98 per standard deviation change, respectively). Restriction to spontaneous preterm births produced similar ORs but with wider $95 \%$ Cls.

Conclusion Considering the personal and social burden of this adverse pregnancy outcome, this finding is of importance for both health care workers and policy makers to provide necessary preventive measures.

Keywords Preterm birth; particulate matter; desert dust; Guadeloupe archipelago; French West Indies

\section{Abbreviations}

$\mathrm{Cl} \quad$ Confidence interval

OR Odds ratio

$\mathrm{PM}_{10} \quad$ Particulate matter $\leq 10 \mu \mathrm{m}$ 


\section{What is already known on this subject}

- Large amounts of mineral dust are transported from the Saharan-Sahel region to the Caribbean Sea, generating peak exposures to particulate matter $\leq 10 \mu \mathrm{m}\left(\mathrm{PM}_{10}\right)$.

- The influence of desert dust particulate pollution on pregnancy outcomes appears plausible.

\section{What are the new findings}

- This research adds new evidence to the health effects of Saharan dust episodes by showing an association between maternal pregnancy exposure (as assessed by the mean $\mathrm{PM}_{10}$ concentration and the proportion of intense dust events) and preterm birth while adjusting for sociodemographic and medical risk factors.

\section{How might this impact on policy or clinical practice in the foreseeable future?}

- Considering the personal and social burden of this adverse pregnancy outcome, this finding is of importance for both health care workers and policy makers to provide necessary preventive measures (such as communicating personalized information to pregnant women about a desert dust cloud moving to the coastline). 


\section{INTRODUCTION}

Desert dust is a natural contributor to atmospheric particulate matter (PM) worldwide. Large amounts of mineral dust are transported from their African sources in the Saharan-Sahel region to the Caribbean Sea. ${ }^{1}$ The archipelago of Guadeloupe (French West Indies) is periodically exposed to desert dust between April and October, generating peak exposures that can last several days and exceed the $P M \leq 10 \mu \mathrm{m}\left(\mathrm{PM}_{10}\right)$ health-based standards (WHO: $20 \mu \mathrm{g} / \mathrm{m}^{3}$, European Union: $40 \mu \mathrm{g} / \mathrm{m}^{3}$, as an annual average).

The available epidemiological evidence of the impact of desert dust episodes on human health is inconsistent. In Europe, although some studies have linked sandy dust storms to a range of adverse health outcomes including respiratory and cardiovascular conditions and mortality, others have found no harmful effect. ${ }^{2}$ The same inconsistencies emerge from studies published more recently. ${ }^{3-6}$ In the Caribbean region, a handful of studies is available. ${ }^{7}$ On the island of Barbados, no relationship was found between desert dust concentrations and asthmatic attendances at the Queen Elizabeth Hospital for the period of $1996-1997,{ }^{8}$ whereas on the island of Trinidad, Saharan dust clouds were associated with increased acute pediatric asthma admissions. ${ }^{9}$ On the island of Martinique, $\mathrm{PM}_{10}$ concentrations were associated with increased hospital admissions for cardiovascular or pulmonary conditions over the period of 2001-2006. ${ }^{10}$ A recent study conducted in the Guadeloupe archipelago found a significant association between the $\mathrm{PM}_{10}$ and $\mathrm{PM}_{2.5-10}$ pollutants contained in the Saharan dust and visits to the emergency department for children with asthma in $2011 .{ }^{11}$ It is worth noting that these studies used an ecological design with time-series analyses, associating a number of health events on a particular day with air pollution levels on the same or recent days.

Regarding maternal exposure to anthropogenic particulate pollution (originating from the burning of fossil fuels in vehicles, power plants or various industrial processes), evidence from available studies is indicative of an association with preterm birth. ${ }^{12}$ Therefore, the influence of desert dust particulate pollution on pregnancy outcomes appears plausible and could be of public health importance because Sahara dust transport may greatly increase the ambient levels of PM (particularly in Southern Europe and in some Atlantic islands). ${ }^{2}$ Surprisingly, to the best of our knowledge, only one study has reported on the influence of Saharan dust episodes on pregnancy (in Spain). ${ }^{13}$

The Guadeloupe archipelago represents a unique opportunity to assess the potential impact of Saharan dust episodes on preterm birth for two main reasons. First, because of the absence of heavy industries and the year-round presence of trade winds (dispersing gaseous and chemical pollutants), anthropogenic particle pollution is low in this area (approximately $20 \mu \mathrm{g} / \mathrm{m}^{3}$ ). ${ }^{14}$ As a result, desert dust natural pollution is the main factor affecting $\mathrm{PM}_{10}$ concentrations. Second, a high rate of 
preterm birth (15.8\%) is observed in Guadeloupe. ${ }^{15}$ This high preterm birth rate is not fully understood, but it could be partly due to the African origin of its population, which as such presents a refractory high rate, common to populations of African descent, irrespective of their current geographic location and independent of socioeconomic status and obstetrical care. ${ }^{16}$ However, other than African ancestry, there is room for other unknown or unstudied risk factors (including environmental exposures) to explain this high rate of preterm births.

Therefore, this study aimed to investigate the impact of Saharan dust episodes on preterm birth among a population of pregnant women in the Guadeloupe archipelago using prospectively collected individual data.

\section{METHODS}

\section{Setting and study design}

Guadeloupe (part of the French West Indies) is an archipelago situated in the Caribbean Sea. It covers an area of $1,628 \mathrm{~km}^{2}$ and has a population of 450,000 inhabitants. This study relies on the TIMOUN mother-child cohort fully described elsewhere. ${ }^{15}$ Briefly, between 2004 and 2007, 1068 women attending check-up visits at public hospitals or dispensaries during their third trimester of pregnancy and having resided in Guadeloupe for more than 3 years were enrolled in the cohort. At inception, the participants completed a standardized questionnaire during a face-to-face interview with midwives. The questionnaire covered sociodemographic characteristics, medical and obstetrical history, and various lifestyle factors. After delivery, information was collected from midwives, pediatricians and hospital medical records about the medical history of the pregnancy, delivery, perinatal conditions, and measurements and health status of the newborn at birth. Following Rouget et al., ${ }^{15}$ we excluded women not born in the Caribbean $(n=110)$, cases involving multiple births $(n=$ $25)$, severe birth defects $(n=8)$ and induced pregnancies after fertility treatment $(n=15)$, resulting in a study sample of 911 women (one case involved both fertility treatment and multiple births).

\section{Preterm births}

Gestational age in weeks was estimated by the obstetricians in charge of follow-up. It was based on the first day of the last menstrual period and was confirmed or corrected by ultrasound. Preterm birth was defined as a birth before 37 completed weeks of gestational age. We distinguished between spontaneous and medically induced preterm birth. The latter results from the induction of delivery due to maternal or fetal factors (either by medication or by caesarean section) before the 
onset of spontaneous labor. Elective induced labor was not practiced at the delivery centers involved in this study.

\section{Desert dust exposure assessment}

Exposure data recorded at the urban background station located in Pointe-à-Pitre (central part of Guadeloupe, latitude $16^{\circ} 14^{\prime} 55^{\prime \prime} \mathrm{N}$, longitude $61^{\circ} 32^{\prime} 36^{\prime \prime} \mathrm{W}$ ) were provided by Gwad'Air (the official air quality monitoring agency for Guadeloupe), from 2005 to 2008. No other air quality monitoring station was operating in the Guadeloupe archipelago during this period of time. The median bird fly distance between the place of residence and the air quality monitoring station siting was $13.03 \mathrm{~km}$ (minimum $0.11 \mathrm{~km}$, maximum $38.89 \mathrm{~km}$ ).

Desert dust episodes were assessed in two ways. First, the mean daily $\mathrm{PM}_{10}$ concentrations ( $\mu \mathrm{g}$ $/ \mathrm{m}^{3}$ ) were considered. However, as we could not distinguish between natural (desert dust) and anthropogenic concentrations, we also used a dust episode index, designed by Gwad'Air for daily transmission to local authorities and assumed to be more specific. It mainly relies on ATMO subindexes, daily indicators of air quality widely used in France. ${ }^{17}$ These sub-indexes, ranging from 1 (very good) to 10 (very poor), are calculated for each of four pollutants (sulphur dioxide, nitrogen dioxide, ozone and $\mathrm{PM}_{10}$ ) on the basis of its concentration compared to a specific reference scale. Drawing upon the ATMO PM 10 sub-index category, the contrasts observed with the other subindexes, and the usual local meteorological conditions, Gwad'Air empirically defines a dust episode index as following: absent (0 to $27 \mu \mathrm{g} \mathrm{PM} 10 / \mathrm{m}^{3}$ ), light (28 to $38 \mu \mathrm{g} \mathrm{PM} \mathrm{P}_{10} / \mathrm{m}^{3}$ ), moderate (39 to $54 \mu \mathrm{g}$ $\left.\mathrm{PM}_{10} / \mathrm{m}^{3}\right)$, and intense $\left(\geq 55 \mu \mathrm{g} \mathrm{PM}_{10} / \mathrm{m}^{3}\right)$. As a categorical exposure estimate, we used the presence of an intense episode. Because of routine maintenance or machine failure independent of any desert dust episodes, there were a few missing days of data $(14,12,21$, and 13 in $2005,2006,2007$, and 2008, respectively).

For each woman, daily measures of $\mathrm{PM}_{10}$ concentrations were averaged over the entire pregnancy, and the proportion of days with intense dust episodes during pregnancy was calculated. However, we had to account for the lack of exposure data in the entire year of 2004, which included two full pregnancies (and 234 partial pregnancies). Therefore, we were forced to exclude those two pregnancies from the study sample. For the 909 remaining women, the number of days with available exposure measurements was used as the denominator of the intense dust episode proportion. 


\section{Covariates}

In-depth statistical analyses have previously resulted in a list of individual risk factors for preterm birth in the TIMOUN cohort. ${ }^{15}$ The corresponding risk factors (all referring to the index pregnancy) were considered in this study as covariates and introduced into the statistical models: place of inclusion (i.e., the healthcare facility where pregnant women were enrolled: University hospital, local hospital, local antenatal care clinic), maternal age $(<20,20-34,>34$ years), marital status (single, living as a couple, single and living with family), years of education $(<5,5-12,>12)$, body mass index $\left(<18.5,18.5-25.0,>25.0 \mathrm{~kg} / \mathrm{m}^{2}\right)$, parity $(0,1, \geq 2)$, prior preterm birth (yes/no), prior miscarriage (yes/no), prior induced abortions (yes/no), lupus (yes/no), history of asthma (yes/no), chronic hypertension (yes/no), gestational weight gain (<275, 275-675, > $675 \mathrm{~g} /$ week), gestational hypertension (yes/no), gestational diabetes (yes/no), urinary tract infection (yes/no), and sex of the newborn (male/female).

\section{Data analysis}

Multivariate logistic regression models were used to produce odds ratios (ORs) and their $95 \%$ confidence intervals ( $\mathrm{Cls}$ ) for associations between desert dust exposure and preterm birth while adjusting for all individual risk factors previously described. As exposure estimates, averaged $\mathrm{PM}_{10}$ concentrations and the proportion of intense dust episodes during pregnancy were considered in turn. To compare the impact of both exposure estimates, we calculated the ORs per standard deviation change $\left(3.08 \mu \mathrm{g} / \mathrm{m}^{3}\right.$ and $4.06 \%$ for the mean $\mathrm{PM}_{10}$ concentration and the proportion of intense dust episodes, respectively).

To compensate for differences in missing daily exposure measurements, each case in the input data set was weighted by the proportion of gestation length with available exposure measurements. Therefore, the more complete the exposure assessment, the more important the observation. We repeated analyses considering spontaneous and medically induced preterm births separately.

Statistical analyses were performed using R software (R Foundation for Statistical Computing, Vienna, Austria, 2018).

\section{RESULTS}

\section{Characteristics of the study population}

The women's pregnancies in this study occurred during the time period from 30 March 2004 to 30 July 2007. The sociodemographic and lifestyle factors of the study population are reported in Table 1. 
Most women were enrolled in the study at the University Hospital, were aged between 20 and 34 years old, were living with a partner and had completed between 5 and 12 years of education. Approximately two-fifths were overweight or obese before pregnancy.

Table 1 Distribution of sociodemographic and lifestyle factors in the study population ( $\mathrm{n}=909$, TIMOUN cohort, Guadeloupe archipelago, French West Indies, 2005-2008)

\begin{tabular}{lc}
\hline & $\mathbf{N}(\%)$ \\
\hline Maternal place of birth & \\
Guadeloupe or Martinique & $795(87.4)$ \\
Other Caribbean islands & $114(12.6)$ \\
Place of inclusion & \\
University hospital & $605(66.6)$ \\
Local hospital & $222(24.4)$ \\
Local antenatal care clinic & $82(9.0)$ \\
Maternal age (years) & \\
$<20$ & $74(8.1)$ \\
$20-34$ & $535(58.9)$ \\
$>34$ & $300(33.0)$ \\
Marital status & \\
Single & $229(25.2)$ \\
Living with partner & $466(51.4)$ \\
Single living with family & $189(20.8)$ \\
Missing & $25(2.6)$ \\
Education (years) & \\
$<5$ & $62(6.8)$ \\
$5-12$ & $663(73.0)$ \\
$>12$ & $184(20.2)$ \\
Body mass index (kg/m²) & \\
$<18.5$ & $55(6.1)$ \\
$18.5-25.0$ & $455(50.0)$ \\
Missing & $379(41.7)$ \\
Mother's employment during pregnancy & \\
Yes & \\
No & \\
Missing & \\
\hline & \\
& \\
\hline &
\end{tabular}


Regarding the outcome, 142 women (15.6\%) delivered preterm among the 909 total women: 67 of them (47.2\%) were spontaneous preterm births, and 74 (52.1\%) were medically induced preterm births (for one woman, the type of preterm birth could not be identified).

\section{Characteristics of exposure}

The average $\mathrm{PM}_{10}$ concentration observed during the time period of $2005-2008$ was $26.78 \mu \mathrm{g} / \mathrm{m}^{3}$. Table 2 presents the distribution of desert dust exposure estimates during pregnancy for the entire cohort and according to the outcome (term / preterm birth). Mean $\mathrm{PM}_{10}$ concentrations ranged from 13.17 to $34.92 \mu \mathrm{g} / \mathrm{m}^{3}$, whereas the proportion of intense dust events ranged from 0.00 to $19.41 \%$. Figure 1 describes the cumulative distribution of both exposure estimates according to term/preterm births. Distributions are shifted to the right for preterm births, above $28 \mu \mathrm{g} \mathrm{PM} 10 / \mathrm{m}^{3}$ (Figure 1a) and $7 \%$ of intense dust episodes (Figure $1 \mathrm{~b}$ ).

Table 2 Descriptive statistics of desert dust exposure estimates during pregnancy on the entire study population and according to the mode of onset of labor (TIMOUN cohort, Guadeloupe archipelago, French West Indies, 2005-2008)

\begin{tabular}{|c|c|c|c|c|}
\hline & $\mathbf{N}$ & Mean \pm SD & Min & Max \\
\hline \multicolumn{5}{|c|}{$\mathrm{PM}_{10}$ concentrations $\left(\mu \mathrm{g} / \mathrm{m}^{3}\right)$} \\
\hline Whole cohort & 909 & $27.15 \pm 3.08$ & 13.17 & 34.92 \\
\hline Term birth & 767 & $27.09 \pm 2.96$ & 13.17 & 31.36 \\
\hline Preterm birth & 142 & $27.49 \pm 3.68$ & 14.82 & 34.92 \\
\hline \multicolumn{5}{|c|}{ Proportion of intense desert dust episodes (\%) } \\
\hline Whole cohort & 909 & $7.73 \pm 4.06$ & 0.00 & 19.41 \\
\hline Term birth & 767 & $7.61 \pm 3.91$ & 0.00 & 14.74 \\
\hline Preterm birth & 142 & $8.34 \pm 4.77$ & 0.00 & 19.41 \\
\hline
\end{tabular}

\section{Associations between preterm birth and desert dust exposure}

Table 3 presents the crude and adjusted associations between desert exposure estimates and preterm births. Except for the association between spontaneous preterm births and mean $\mathrm{PM}_{10}$ concentrations, the crude and adjusted ORs were very similar.

When considering all preterm births, increased adjusted ORs were found for both the mean $\mathrm{PM}_{10}$ concentrations and the proportion of intense dust events (OR 1.40,95\% $\mathrm{Cl} 1.08$ to $1.81, \mathrm{p}=0.01$ and OR $1.54,95 \% \mathrm{Cl} 1.21$ to $1.98, \mathrm{p}=0.0006$ respectively). To determine whether these associations vary 
with distance to the monitoring station (potentially reflecting some exposure misclassification), we introduced an interaction term between distance (split at the median) and exposure estimates into the regression models. No significant interaction effects were observed $(p=0.75$ and $p=0.52$, for the mean $\mathrm{PM}_{10}$ concentration and the proportion of intense dust episodes, respectively).

Table 3 Crude and adjusted Odds Ratios for the risk of preterm birth according to desert dust exposure estimates and mode of onset of labor (TIMOUN cohort, Guadeloupe archipelago, French West Indies, 2005-2008)

\begin{tabular}{|c|c|c|c|c|c|c|}
\hline \multirow{2}{*}{ Desert dust exposure estimates } & \multirow{2}{*}{$\begin{array}{c}\text { No. of } \\
\text { preterm } \\
\text { births }^{*}\end{array}$} & \multirow{2}{*}{$\begin{array}{l}\text { No. of } \\
\text { term } \\
\text { births }\end{array}$} & \multicolumn{2}{|c|}{ Crude } & \multicolumn{2}{|c|}{ Adjusted $^{+}$} \\
\hline & & & $\mathrm{OR}^{\ddagger}$ & $95 \% \mathrm{Cl}$ & $\mathrm{OR}^{\ddagger}$ & $95 \% \mathrm{Cl}$ \\
\hline All births & 142 & 767 & & & & \\
\hline $\mathrm{PM}_{10}$ concentrations $\left(3.08 \mu \mathrm{g} / \mathrm{m}^{3}\right)$ & & & 1.36 & $1.07,1.72$ & 1.40 & $1.08,1.81$ \\
\hline Proportion of intense desert dust episodes (4.06\%) & & & 1.38 & $1.11,1.72$ & 1.54 & $1.21,1.98$ \\
\hline Spontaneous preterm and term births & 67 & 767 & & & & \\
\hline $\mathrm{PM}_{10}$ concentrations $\left(3.08 \mu \mathrm{g} / \mathrm{m}^{3}\right)$ & & & 1.44 & $1.01,2.05$ & 1.39 & $0.93,2.06$ \\
\hline Proportion of intense desert dust episodes (4.06\%) & & & 1.53 & $1.11,2.10$ & 1.63 & $1.13,2.35$ \\
\hline Induced preterm and term births & 74 & 767 & & & & \\
\hline $\mathrm{PM}_{10}$ concentrations $\left(3.08 \mu \mathrm{g} / \mathrm{m}^{3}\right)$ & & & 1.28 & $0.93,1.76$ & 1.30 & $0.91,1.86$ \\
\hline Proportion of intense desert dust episodes (4.06\%) & & & 1.25 & $0.93,1.68$ & 1.35 & $0.96,1.90$ \\
\hline
\end{tabular}

Abbreviations: $\mathrm{Cl}$, confidence interval; OR, odds ratio; PTB, preterm birth.

*For one woman, the type of preterm birth was unknown.

${ }^{\dagger}$ The covariates for which we adjusted were place of inclusion, maternal age, marital status, years of education, body mass index, parity, prior preterm birth, prior miscarriage, prior induced abortions, lupus, asthma, chronic hypertension, gestational weight gain, gestational hypertension, gestational diabetes, urinary tract infection, sex of the newborn.

${ }^{\ddagger}$ The odds ratios were calculated per standard deviation change.

Restriction to spontaneous preterm births produced similar adjusted ORs but with wider $95 \% \mathrm{Cls}$ (OR 1.39, $95 \% \mathrm{Cl} 0.93$ to $2.06, \mathrm{p}=0.10$ and $\mathrm{OR} 1.63,95 \% \mathrm{Cl} 1.13$ to $2.35, \mathrm{p}=0.009$ for mean $\mathrm{PM}_{10}$ concentrations and the proportion of intense dust events, respectively). Regarding induced preterm births, lower ORs were found, but they were still greater than one (with Cls including unity). 


\section{DISCUSSION}

This research adds new evidence to the health effects of Saharan dust episodes by showing an association between maternal pregnancy exposure (as assessed by the mean $\mathrm{PM}_{10}$ concentration and the proportion of intense dust events) and preterm birth.

The present study has many strengths, including the study setting, the longitudinal design, and extensive information on covariates. Guadeloupe can be considered a natural laboratory for disentangling the influence of desert dust natural pollution and anthropogenic pollution because according to Euphrasie-Clotilde et al., ${ }^{14}$ on average, the concentration of anthropogenic pollution does not exceed $20 \mu \mathrm{g} \mathrm{PM} 10 / \mathrm{m}^{3}$ (despite some possible traffic-related pollution hot-spots). This study took advantage of the TIMOUN mother-child cohort, an archipelago-wide cohort, that collected information on potential maternal socioeconomic, behavioral, and medical confounders at an early stage of pregnancy and therefore before outcomes occurred. To minimize residual confounding, we deliberately adjusted for numerous risk factors highlighted previously by Rouget et al. ${ }^{15}$

However, this study has some limitations. Exposure to Saharan dust was assessed through one single background air quality monitoring station (situated in the center of Guadeloupe) regardless of the subject's residential location. These monitor-based estimates may have introduced some nondifferential measurement error for pregnant women living far from the monitoring station due to the presumed spatial heterogeneity of air pollutants relating to topography and local micro sources, although the absence of interaction with distance to the monitoring station is reassuring. Alternative exposure estimates could be derived from desert dust modeling (such as the Navy Aerosol Analysis and Prediction System - NAAPS - model) or from satellite imagery (such as the Moderate Resolution Imaging Spectroradiometer - MODIS - aerosol optical thickness product). However, considering the lower accuracy of these proxies and the need for retrospective exposure assessment (time period of 2004-2008), we preferred to rely on a well-established ground-based instrument. The population size and the number of events may appear modest but do not limit the statistical power of the analysis to identify significant findings.

In the Guadeloupe archipelago, the average $\mathrm{PM}_{10}$ concentration observed during the time period of 2005-2008 $\left(26.78 \mu \mathrm{g} / \mathrm{m}^{3}\right)$ ranks high compared to those observed in the seventeenth largest French cities (mainland France) during the time period of 2007-2010 (range: 19.3 to $31.8 \mu \mathrm{g}$ $\left.\mathrm{PM}_{10} / \mathrm{m}^{3}\right) .{ }^{18}$ Associations are consistent across exposure estimates when calculating ORs per standard deviation change suggesting that $\mathrm{PM}_{10}$ concentrations recorded at the urban background monitoring station correctly reflect desert dust concentrations. Because the adjusted ORs do not contrast with the crude ORs, the potential for confounding is small. In other words, these results suggest that desert dust episodes influence preterm birth above and beyond the wide range of established risk 
factors. That higher ORs were found for spontaneous preterm births than medically induced preterm births is not unexpected. Although some underlying disorders are common to both outcomes (e.g., preeclampsia), other specific conditions that cause induced preterm births are not assumed to be influenced by prenatal air pollution exposure, although a recent case-crossover study suggested that a short-term increase in $\mathrm{PM}_{2.5}$ concentrations is a potential trigger of placental abruption. ${ }^{19}$

The underlying biological pathways of the effect of particulate pollution on pregnancy are complex and multiple, given the chemical and physical heterogeneity of air pollutants and the various stages of fetal vulnerability during pregnancy. Researchers have, however, suggested the alteration of maternal-placental exchanges, endocrine disruption, oxidative pathways and alteration of maternal host-defense mechanisms as possible mechanisms. ${ }^{20}$ However, compared to anthropogenic particle pollution, coarse particles coming from desert sources could bring their own toxicity because desert dust clouds carry heavy metals and biological components (such as bacteria, viruses, fungi and endotoxins) to the downwind countries. ${ }^{21}$

At variance with our results, Dadvand et al. ${ }^{13}$ observed a small but statistically significant increase in gestational age at delivery in association with the number of episodic days during the third trimester and entire pregnancy. However, their study was conducted in another geographical region, with differences in climate pattern, distance from dust sources and morphology or chemical composition of the particles.

In conclusion, the current study suggests that exposure to desert dust episodes is associated with preterm birth, while adjusting for sociodemographic and medical risk factors. Considering the personal and social burden of this adverse pregnancy outcome, we believe that this finding is of importance for both health care workers and policy makers to provide necessary preventive measures (such as communicating personalized information to pregnant women about a desert dust cloud moving to the coastline). 


\section{Acknowledgements}

We thank Sylvaine Cordier for implementing the TIMOUN cohort. We are indebted to Léah Michineau, Christine Monfort, and Céline Garbin for valuable technical assistance. We thank our partners in the BrumiSaTerre research team (Stéphanie Guyomard, Antoine Talarmin, Séverine Ferdinand, Erika Upegui, Fabien Mercier, and Gülen Ayhan) for fruitful discussions.

Contributors JFV generated the idea for the paper and prepared an analytical plan. YM and JFV conducted all data analyses. JFV prepared the first draft on which all co-authors commented.

Funding This work was supported by the French National Research Program for Environmental and Occupational Health of ANSES (EST-2016/1/015).

Competing interests None declared

Patient consent Written informed consent was obtained from all pregnant women included in the study.

Ethics approval This study was approved by the Guadeloupean Ethics Committee for studies involving human subjects. 


\section{REFERENCES}

1. Prospero JM, Mayol-Bracero O. Understanding the transport and impact of African dust on the Caribbean basin. Bull Amer Meteor Soc 2013;94:1329-37.

2. Karanasiou A, Moreno N, Moreno T, et al. Health effects from Sahara dust episodes in Europe: literature review and research gaps. Environ Int 2012;47:107-14.

3. Neophytou AM, Yiallouros P, Coull BA, et al. 2013. Particulate matter concentrations during desert dust outbreaks and daily mortality in Nicosia, Cyprus. J Expo Sci Environ Epidemiol 2013;23:27580 .

4. Alessandrini ER, Stafoggia M, Faustini A, et al. 2013. Saharan dust and the association between particulate matter and daily hospitalisations in Rome, Italy. Occup Environ Med 2013;70:432-4.

5. Reyes M, Díaz J, Tobias A, et al. Impact of Saharan dust particles on hospital admissions in Madrid (Spain). Int J Environ Health Res 2014:24:63-72.

6. Stafoggia M, Zauli-Sajani S, Pey J, et al. Desert dust outbreaks in Southern Europe: contribution to daily $\mathrm{PM}_{10}$ concentrations and short-term associations with mortality and hospital admissions. Environ Health Perspect 2016:124:413-9.

7. Monteil MA. Saharan dust clouds and human health in the English-speaking Caribbean: what we know and don't know. Environ Geochem Health 2008;30:339-43.

8. Prospero JM, Blades E, Naidu R, et al. Relationship between African dust carried in the Atlantic trade winds and surges in pediatric asthma attendances in the Caribbean. Int J Biometeorol 2008;52:823-32.

9. Gyan K, Henry W, Lacaille S, Laloo A, et al. African dust clouds are associated with increased paedriatric asthma accident and emergency admissions on the Caribbean island of Trinidad. Int $J$ Biometeorol 2005;49:371-6.

10. Blateau A, Bouobda D, Le Tertre A, et al. Health effects from desert dust episodes in Martinique, 2001-2006 [in French]. Bull Veille Sanit Antilles Guyane 2012;3:11-5.

11. Cadelis G, Tourres R, Molinie J. Short-term effects of the particulate pollutants contained in Saharan dust on the visits of children to the emergency department due to asthmatic conditions in Guadeloupe (French Archipelago of the Caribbean). PLoS One 2014;9:e91136.

12. Stieb DM, Chen L, Eshoul M, et al. Ambient air pollution, birthweight and preterm birth: a systematic review and meta-analysis. Environ Res 2012;117:100-11.

13. Dadvand P, Basagaña X, Figueras F, et al. Saharan dust episodes and pregnancy. J Environ Monit 2011;13:3222-8.

14. Euphrasie-Clotilde L, Molinié J, Feuillard T, et al. The relationship between coastal West African dust level and Caribbean island dust. In: David Almorza Gomar D, Longhurst JWS, Brebbia CA, 
Barnes J, eds. WIT transactions on ecology and the environment. Southampton : WIT Press; 2017:211;121-8.

15. Rouget F, Lebreton J, Kadhel P, et al. Medical and sociodemographic risk factors for preterm birth in a French Caribbean population of African descent. Matern Child Health J 2013;17:1103-11.

16. Muglia LJ, Katz M. The enigma of spontaneous preterm birth. NEJM 2010;362:529-35.

17. van den Elshout S, Léger K, Nussio F. Comparing urban air quality in Europe in real time. A review of existing air quality indices and the proposal of a common alternative. Environ Int 2008;34:7206.

18. Corso $\mathrm{M}$, Pascal $\mathrm{M}$, Wagner V, et al. Short-term impacts of particulate matter $\left(\mathrm{PM}_{10}\right)$ on mortality in 17 French cities, 2007-2010 [in French]. Bull Epidémiol Hebd 2015;1-2:14-20.

19. Ananth CV, Kioumourtzoglou MA, Huang Y, et al. Exposures to air pollution and risk of acuteonset placental abruption: a case-crossover study. Epidemiology 2018;29:631-8.

20. Slama R, Darrow L, Parker J, et al. Meeting report: atmospheric pollution and human reproduction. Environ Health Perspect 2008;116:791-8.

21. Morman SA, Plumlee GS. The role of airborne mineral dusts in human disease. Aeolian Res 2013:9;203-12. 
Figure 1 Cumulative distribution of the mean $\mathrm{PM}_{10}$ concentration $\left(\mu \mathrm{g} / \mathrm{m}^{3}\right)(\mathrm{A})$ and the proportion of intense dust episodes (B) during pregnancy according to term (thick points) / preterm (thin points) births (TIMOUN cohort, Guadeloupe archipelago, French West Indies, 2005-2007).
